\title{
The Influence of Certain Socio-Demographic and Economic Factors for the Need of Orthodontic Treatment
}

\author{
Yulia Bogdanova Peeva \\ Department of Social Medicine and Public Health, Faculty of Public Health, Medical University, Plovdiv, Bulgaria \\ Email: julipeeva@abv.bg
}

How to cite this paper: Peeva, Y.B. (2017) The Influence of Certain Socio-Demographic and Economic Factors for the Need of Orthodontic Treatment. Open Access Library Journal, 4: e4112.

https://doi.org/10.4236/oalib.1104112

Received: November 2, 2017

Accepted: November 26, 2017

Published: November 29, 2017

Copyright (c) 2017 by author and Open Access Library Inc.

This work is licensed under the Creative Commons Attribution International License (CC BY 4.0).

http://creativecommons.org/licenses/by/4.0/

\section{(c) () Open Access}

\begin{abstract}
The present study is aimed at analyzing the respondents between sociodemographic and economic factors on one side, and patient's expectation, on the other, with the need of orthodontic treatment. Material and methods: By using a sociological method of straight-group questionnaire the subjects ( 89 young adults) of experimental and control group have been asked to take into account factors such as age and sex, oral-health and perceptions of treatment. Dental aesthetics is assessed by means of the aesthetics component of the Visual Analogue Scale (VAS). By using Visual Analogue Scale every one of the undergraduates self-assessed one's own dental esthetics with the choice of a number of means. The results support the conclusion that favourable dental esthetics and previous orthodontic treatment appear as important variables that affect patient's attitude towards orthodontic treatment.
\end{abstract}

\section{Subject Areas}

Public Health

\section{Keywords}

Socio-Demographic and Economic Factors, Orthodontic Treatment, Visual Analogue Scale (VAS), Health-Related Quality of Life

\section{Introduction}

Each patient is situated at a different position from routine in visiting dental practice. It is known that most patients, seeking dental care present a higher or smaller degree of stress. Majority of patients develop a degree of anxiety, depending on education, type of dental treatment or dentist's behavior and that 
may be a result from the past, whereas others feel comfortable and they are pleased to be treated [1].

Over the last 15 years, the terms "Quality of life" and "Health-related quality of life" have been seen increasingly in medical literature. There is still little research in the field of orthodontics and health-related quality of life. The conclusion as to whether orthodontic treatment of dentofacial deformities fit into the classic concept of health and disease is a difficult one [2]. One of the reasons frequently stated for undertaking orthodontic treatment is improvement in aesthetics and subsequent enhancement of psycho-social well-being [3]. It is thought that regularity of the dental arches might facilitate oral hygiene, and prevention of caries and periodontal disease is thus a perceived benefit of orthodontic treatment [4].

Quality of life may be defined as a person's sense of well-being that stems from satisfaction or dissatisfaction with the areas of life that are important to him/her.

The last tendency for quality of life, applied to oral health, allows it to be oriented to different social groups. And that's the way to positive patient's attitudes and social opinion about dental treatment [1] [5]. Sometimes, low economic opportunities of the Bulgarian consumers of dental services define negative social attitude to the dentists. In particular, present incomes of the most ofBulgarians put themselves in a restricted access to implantology and orthodontic treatment.

\section{Aim}

The aim of the present study is to investigate of certain socio-demographic and economic components and their influence for the need of orthodontic treatment.

\section{Materials and Methods}

By using a sociological method of straight-group questionnaire the subjects have been asked to consider factors such as age and gender, oral health, according to expectations of needed orthodontic treatment and self-assessed dental esthetics [6]. In orderly to objectify statistical data a numerical scale-Visual Analogue Scale (VAS) was introduced [7] [8]. By using Visual Analogue Scale every one of the undergraduates self-assessed its own dental esthetics with the choice of a number of means. The whole range $0-100$ points has been divided into the following assessment groups:

- From 0 to $24-$ poor esthetics

- From 25 to 49 -not very bad

- From 50 to 74-good esthetics

- From 75 to $99-$ very good esthetics

- 100 points-perfect esthetics (ideal occlusion) [9]-[16].

Statistical data are discussed by means of variation and nonparametric ana- 
lyses. Findings and graphics are presented by computer software programs SPSS ver. 17.

\section{Results}

The sample comprises 89 young adults from 22 to 34 years old. The experimental group is composed of 45 undergraduates from Medical University of Plovdiv. All of them are dental medicine students who being trained as dentists and acquiring of competences in the specialty. There are 44 undergraduates in the control group getting their professional competence as engineers at University of Food Technologies of Plovdiv without any dental education.

The mean age of the subjects in the experimental group is $24.90 \pm 0.35$ years. The mean age of the control group is $25.43 \pm 0.7$ years. Respondents from the experimental group have highest relative proportions of presentation in the age of 20 - 24 years $-56.53 \pm 7.10$. The results are presented in Table 1 :

It is seen in Table 1, that there is no statistical significance in comparing the relative proportions of both groups, $\mathrm{P}>0.05, \mathrm{~F}=0.37$. All of them are undergraduates and this may be explained by the young age of contingents. Satisfaction with dentofacial appearance has also been found in previous studies to correlate with age [10]. Satisfaction with facial body image decreases with age. Consciousness about body image, including dental appearance, seems to increase with age, reaching a peak around the midteens [11].

Previous studies have shown high correlation between socio-economic factors and consciousness for the need of orthodontic treatment [12]. In accordance with Profit criteria (cost-risk-benefit-quality) dental health services are not attainable by Bulgarian consumer just because this service has been for nothing in past 50 years [13].

The results presented in Table 2 show how each respondent explains material status of his/her family. It's interesting to note that no one of the control group assessed himself at a "very good" position. This status is confirmed by $13.3 \% \pm$ $5.06 \%$ of experimental group. Both groups have nearly exposed relatively proportions at other rates of economic status in society.

The analysis of the measures related to the factor "residence" indicated that most of the undergraduates live in town-93.03\% $\pm 3.88 \%$ and only $6.97 \% \pm$ $3.88 \%$ in village. The same is the situation in control group about this factor- $-97.7 \% \pm 2.29 \%$ live in town and $2.30 \% \pm 2.29 \%$-in village. Subjective rating of

Table 1. Respondent's age distribution.

\begin{tabular}{ccccccc}
\hline \multirow{2}{*}{ Age (years) } & \multicolumn{3}{c}{ Experimental group } & \multicolumn{4}{c}{ Control group } \\
\cline { 2 - 7 } & Number & $\%$ & Sp & Number & $\%$ & Sp \\
\hline $20-24$ & 27 & 56.53 & 7.10 & 25 & 61.36 & 7.34 \\
$25-29$ & 16 & 39.00 & 3.36 & 7 & 36.36 & 7.25 \\
$30+$ & 2 & 2.47 & 2.44 & 12 & 2.28 & 2.24 \\
All & 45 & 100.00 & - & 44 & 100.00 & - \\
\hline
\end{tabular}


Table 2. General well-being of the family.

\begin{tabular}{ccccccc}
\hline & \multicolumn{3}{c}{ Experimental group } & \multicolumn{3}{c}{ Control group } \\
\cline { 2 - 7 } Economic status & Number & $\%$ & $\mathrm{Sp}$ & Number & $\%$ & $\mathrm{Sp}$ \\
\hline Very good & 6 & 13.3 & 5.06 & - & 0 & - \\
Good & 30 & 66.7 & 7.02 & 34 & 77.27 & 6.31 \\
Poor & 6 & 13.3 & 5.06 & 6 & 13.64 & 5.17 \\
Not sure & 3 & 6.7 & 3.71 & 4 & 9.09 & 4.33 \\
All & 45 & 100.0 & - & 44 & 100.0 & - \\
\hline
\end{tabular}

Table 3. Satisfaction from the received treatment.

\begin{tabular}{ccccccc}
\hline \multirow{2}{*}{ Satisfaction } & \multicolumn{3}{c}{ Experimental group } & \multicolumn{3}{c}{ Control group } \\
\cline { 2 - 7 } & Number & $\%$ & $\mathrm{Sp}$ & Number & $\%$ & $\mathrm{Sp}$ \\
\hline of patient & 24 & 55.81 & 7.57 & 30 & 68.18 & 7.02 \\
of dentist & 7 & 16.28 & 5.62 & 7 & 15.91 & 5.51 \\
of both sides & 12 & 27.90 & 6.84 & 7 & 15.91 & 5.51 \\
All & 43 & 100.0 & - & 44 & 100.0 & - \\
\hline
\end{tabular}

oral health have been used in other recent studies identifying interesting, albeit not objective, relationships to socio-demographic parameters [4] [5] [6].

After some time, unfavourable factors increase the pathology and orthodontic treatment become more expensive [10]. And that is the primary reason for patient's lack of satisfaction from the dental procedure. This conflict points out that the communication between patient and dentist is socio-economic in essence. About the question" What is more important for you-patient satisfaction or dentist's satisfaction from the received treatment?" are presented the next outcomes at Table 3:

To compare data for both groups confirmed that patient satisfaction of the conducted treatment is more important from dentist's opinion to this question $(55.8 \pm 7.57 \%$ for experimental group and $68.18 \% \pm 7.02 \%)$. “The dental profession has to ensure that we are able to justify our treatment plans, based on true clinical need, but also allowing patients to have an acceptable level of input" [3] and ethics is violated in cases of:

- Unsatisfactory treatment,

- Overtreatment,

- Overcharging,

- Convincing patients to accept unnecessary services [14].

The relationships between the need to improve oral aesthetics in the sense of imitation ("Do you know people with braces") and the awareness of students are studied. For the following variables presented in Table 4, Spearman's correlation is significant $\mathrm{P}<0.01$ :

The data from Table 4 shows that the relationship between internet use and social media choice is high $r_{s}=0.84$. In fact, it is assumed that this is a normal 
Table 4. Correlations between imitation as a factor for conducting orthodontic treatment and information via the Internet.

\begin{tabular}{cccc}
\hline Indicators & $\begin{array}{c}\text { Surfing the } \\
\text { Internet }\end{array}$ & $\begin{array}{c}\text { The most commonly } \\
\text { used internet sources }\end{array}$ & $\begin{array}{c}\text { Found helpful } \\
\text { information }\end{array}$ \\
\hline Surfing the Internet & & 0.84 & 0.69 \\
The most commonly used internet sources & 0.84 & & 0.55 \\
Found helpful information & 0.69 & 0.55 & \\
\hline
\end{tabular}

${ }^{*}$ Correlations are significant at $\mathrm{P}<0.01$.

manifestation of the possibility of more information when using the Internet. Internet is the possibility that any information found is useful to the potential patient who is interested in the stages associated with orthodontic treatment. This relationship is positive and significant $-r_{s}=0.69$. When specifying the Internet sources, the useful information found shows less dependence, but still remains significant $-r_{s}=0.55(P<0.01)$. This fact gives reason to believe that the children who participated in the survey tend to trust the information they find on the Internet.

It is interesting to know how young people with varying dental esthetics forms their criteria about self-assessed dental image, smile and good oral-health. By using Visual Analogue Scale every one of the undergraduates self-assessed its own dental esthetics with the choice of a number of means.

The mean of VAS for the experimental group approaches to a "very good esthetics" division-75.72 $\pm 3.47 \mathrm{p}$. With 100 points are only $9.3 \%$ self-esteemed. This result explains due to stability knowledge and self-confidence of undergraduates in answering (decision) of their own oral-health problems. The mean value for age and VAS leave a space for subsistence of a significant feedback between age and VAS. Further research is required to establish the feedback correlation.

\section{Conclusions}

1) These findings suggest that there is a statistical significance of satisfaction from the dental esthetics in compared groups, $\mathrm{P}<0.05$. This fact is due to the higher educational criteria of undergraduates learning dental medicine. The students without medical education show higher satisfaction from their oral and facial image.

2) A significant correlation is invariant over age, sex and education in forming perceptions of needed orthodontic treatment and self-assessed dental esthetics.

3) The results confirm that favourable dental esthetics and previous orthodontic treatment are important variables in explaining certain socio-demographic and economic factors.

\section{References}

[1] McComb, O.K. (1996) Do Dentists Refer Orthodontic Patients Inappropriately? 
British Dental Journal, 181, 132-136. https://doi.org/10.1038/sj.bdj.4809188

[2] Spyropoulos, M. (2006) Ethics in the Pursuit of Esthetics. Lingl News J, 4, 2

[3] Cunningham, S. and Hunt, N. (2001) Quality of Life and Its Importance in Orthodontics. European Journal of Orthodontics, 28, 2

[4] Maia, N., Normando, A., Feitosa, M., et al. (2010) Factors Associated to Orthodontic Stability-A Longitudinal Retrospective Study of 209 Patients. Journal of Orthodontics, 11, 61-66.

[5] Pratelli, P., Gielbier, S. et al. (1998) Parental Perceptions and Attitudes on Orthodontic Care. British Journal of Orthodontics, 25, 41-46. https://doi.org/10.1093/ortho/25.1.41

[6] Kuroda, S., et al. (2010) Relationship between Orthodontic Expertise and Perception of Treatment Needs for Maxillary Protrusion: Comparison of Dental Students, Residents, and Orthodontists, American Journal of Orthodontics and Dentofacial Orthopedics, 137, 340-345. https://doi.org/10.1016/j.ajodo.2008.04.029

[7] Maxwell, C. (1978) Sensitivity and Accuracy of the Visual Analogue Scale: A Psycho-Physical Classroom Experiment. British Journal of Clinical Pharmacology, 6, 15-24. https://doi.org/10.1111/j.1365-2125.1978.tb01676.x

[8] Ramya, R., Ajithkrishnan, C.G. and Thanveer, K. (2014) Development and Psychometric Testing of a Visual Analog Scale for Dental Fluorosis. Journal of Indian Association of Public Health Dentistry, 12, 4-8.

https://doi.org/10.4103/2319-5932.138898

[9] Luyk, N., Beck, F. and Weaver, J. (1988) A Visual Analogue Scale in the Assessment of Dental Anxiety. Anesthesia Progress, 35, 121-123.

[10] Bos, A., Hoogstraten, J. and Prahl-Andersen, B. (2003) Expectations of Treatment and Satisfaction with Dentofacial Appearance in Young Adults. American Journal of Orthodontics and Dentofacial Orthopedics, 123, 127-132. https://doi.org/10.1067/mod.2003.84

[11] Hussey, D. (2002) Where Is the Ethics in Cosmetic Dentistry? British Dental Journal, 192, 356-357. https://doi.org/10.1038/sj.bdj.4801374

[12] Tulloch, J. and Shaw, W. (1984) A Comparison of Attitudes toward Orthodontic Treatment in British and American Communities. American Journal of Orthodontics, 85, 253-259. https://doi.org/10.1016/0002-9416(84)90064-2

[13] European Federation of Orthodontic Specialists Associations (2010) European Orthodontic Insurance Report.

[14] DiMatteo, M., McBride, C.A., et al. (1995) Public Attitudes toward Dentists: A U.S. Household Survey. JADA, 126, 1563-1570. https://doi.org/10.14219/jada.archive.1995.0089

[15] Russell, J. and Pearson, A. (1999) The Consultant Orthodontist Service 1998 Survey. British Dental Journal, 187, 149-153.

[16] Abraham, W.T. and Russell, D.W. (2008). Statistical Power Analysis in Psychological Research. Social and Personality Psychology Compass, 2, 283-301. https://doi.org/10.1111/j.1751-9004.2007.00052.x 